\title{
A Perspective on the Consequences for Insect Herbivores and Their Natural Enemies When They Share Plant Resources
}

\author{
Patrik Kehrli1, 2 and Steve D. Wratten ${ }^{1}$ \\ ${ }^{1}$ Bio-Protection Research Centre, Lincoln University, P.O. Box 84, Liacoln 7647, Canterbury, New Zealand \\ ${ }^{2}$ Département Protection des Végétaux Grandes Cultures et Vigne/Viticulture et Oenologie, Group Entomologie, Station de Recherche \\ Agroscope Changins-Wädenswil ACW, CP 10121260 Nyon, Switzerland
}

Correspondence should be addressed to Patrik Kehrli, patrik.kehrli@acw.admin.ch

Received 1 February 2011; Accepted 13 March 2011

Academic Editor: A. Chappelka

Copyright ( 2011 P. Kehrli and S. D. Wratten. This is an open access article distributed under the Creative Commons Attribution License, which permits unrestricted use, distribution, and reproduction in any medium, provided the original work is properly cited.

Thousands of insect species consume both animal and plant-derived food resources. However, little recognition is given to the fact that omnivory is a general feeding strategy common to all higher trophic levels. Species in multitrophic interactions can all directly rely on the same plant resources. Nonetheless, little is known about the effect of a change in the relative abundance of a shared plant resource on trophic dynamics. Here we describe how a relative change of resource availability can affect multitrophic interactions and we emphasise its importance. Changes in multitrophic interactions can be induced by unequal alterations of individual fitness across trophic levels, possibly leading to changes in population structure of interacting species. At least ten ecological mechanisms can be involved and these are explored here. It is concluded that shared plant resources that are differentially used over several trophic levels have the potential to modify community structure and energy flow within food webs and ecosystems in more complex ways than previously recognised. The synthesis presented here provides an understanding of this complexity and can lead to improved deployment of biodiversity when manipulating food webs to protect ecological communities or to enhance ecosystem services such as biological control of agricultural pests.

\section{Introduction}

Herbivores are trapped between "the devil and the deep blue sea", that is, between natural enemies and plant defences [1-4]. However, little recognition is given to the fact that many natural enemies also directly rely on plant-derived food resources, such as nectar, pollen, seeds, or leaves [58]. Thousands of species of terrestrial arthropods such as predatory carabids, coccinellids, mites, spiders, and syrphids, along with hymenopteran and dipteran parasitoids, consume both animal and plant food; that is, they are omnivores $[9,10]$. Omnivores can feed on animal-and plant-derived resources throughout their life, as can coccinellids, or utilise animal and plant food in different life stages, exhibiting life-history omnivory [11]. Examples are syrphids and parasitoids $[9,12]$. Supplementing prey diet with plant food increases the individual fitness of omnivorous natural enemies $[12,13]$ and also sustains natural enemy populations when prey or hosts are scarce [11]. Hence, omnivory can promote top-down control [14]. Altogether, omnivores are important and persistent regulators of herbivore populations [15].

Omnivory can be found in species that are usually considered to be primary consumers (e.g., grasshoppers), in intermediate secondary consumers (e.g., predatory arthropods) and in top predators, such as bears or humans. Species in multitrophic interactions can therefore all directly rely on the same plant resources [14]. For example, floral nectar is frequently shared between butterflies, their para-sitoids, and their hyperparasitoids (parasitoids whose hosts are other parasitoids) as a consequence of the spatial and temporal proximity of these organisms [16-18]. It is therefore common among arthropods that consumers in the herbivorous second (herbivores), the omnivorous third (natural enemies), and the omnivorous fourth trophic level (antagonists) all forage on shared plant resources (see Figure 1). However, 


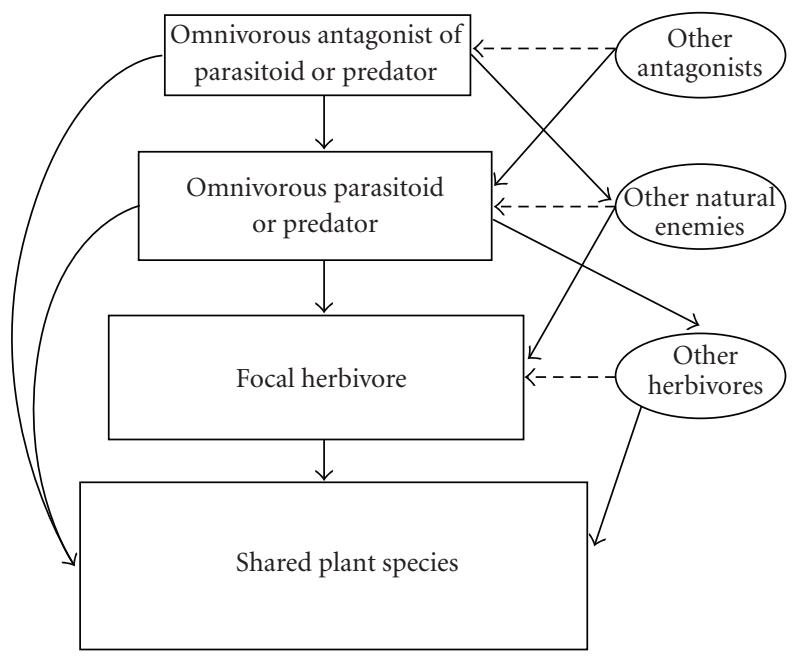

Figure 1: The main direct and indirect interactions among second trophic level herbivores, omnivores in the third trophic level, and omnivorous fourth trophic level consumers foraging on a shared plant resource. Solid arrows indicate consumer-resource interactions whereas dotted ones indicate indirect interactions, such as interspecific competition. For simplicity, other interactions such as intraguild predation, apparent competition, and prey defensive responses are not illustrated. See text for detailed explanations.

little is known about the effect of a change in the relative abundance of a shared plant resource such as nectar on food web structure and dynamics. This perspective is to our knowledge the first synthesis of the mechanisms in which differences in the abundance or quality of shared plant resources can lead to asymmetrical fitness changes between and even within trophic levels. We describe how such a change of resource availability can affect trophic cascades, and we emphasise the importance of this for community ecology and biological control.

\section{How Can Shared Plant Resources Alter Trophic Cascades?}

Trophic cascades are defined as reciprocal consumerresource relationships that alter the abundance, biomass, or productivity of species' populations across several trophic levels of a food chain [19]. A change in the relative availability of a shared plant species can therefore not only affect the trophic interactions between herbivores, omnivorous natural enemies, and omnivorous antagonists, but also alter the trophic cascade within a subset of the food web community ("species-level cascades" sensu 2). Changes in species-level cascades are induced either by unequal alterations of individual fitness across the different trophic levels or by modification of the population structures of herbivores, natural enemies, and antagonists. At the level of individuals, relatively stronger fitness alterations at one level compared with the other two may result from different effects of changes in resource availability on the reproductive success of species [20-24]. At the population level, such changes can alter the sex ratio of offspring across trophic levels [25]. This is particularly important for parasitoids and hyperparasitoids because only females attack the herbivorous host. A higher proportion of parasitoid females in a population lead to increased parasitism rates, and this can lead to greater herbivore population suppression (see [26]). However, a higher proportion of hyperparasitoid females can lead to increased suppression of herbivores' natural enemies and consequently reduced top-down control of herbivores.

\section{How Are Species-Level Trophic Cascades Triggered?}

A key question is how changes in relative availability of shared plant resources can have different effects on individual fitness or population structure across trophic levels. These effects can result from relative differences in the abundance, quality, or availability of shared plant resources, which can therefore favour one level of the trophic cascade over others by a range of mechanisms. These are summarised in Table 1 and are discussed in more detail here. (1) It is well known that the access of insects to floral nectar is determined by flower morphology [27]. (2) The attractiveness of plants, for example, shape, colour, and odour can differentially influence consumer guilds [27]. (3) Species in a trophic cascade are differentially affected by the chemical composition of plants, particularly the "secondary" compounds that determine the palatability of leaves, seeds, and pollen [28, 29]. Even easily accessible nectar differs in its sugar composition [30,31], and Wäckers [32] showed that nectar consumers differ considerably in their demand for particular saccharides. Thus, even if a plant resource can be accessed by a number of consumer species, it may differentially affect them. (4) The temporal distribution of plant resource availability may favour one trophic level relative to the others because their phenology may only partially coincide [33]. (5) Mobility varies among species. Therefore, the spatial distribution of plant resources 
TABLE 1: A summary of how differences in the abundance, availability or quality of a shared plant resource can lead to an asymmetrical enhancement of fitness across trophic levels. See text for references.

(1) Plant morphology

(2) The attractiveness of plant resources

(3) The nutritional value and chemical composition of plants

(4) The temporal availability of plant resources

(5) The spatial distribution of plants

The extent of species-specific reliance on the shared resource

Species-specific numerical and functional responses to the shared resource

Interactions with other organisms, such as competitors, pollinators, alternative prey, and intra- and interguild predators

Behavioural changes in species, such as predator avoidance behaviour prey defensive responses

Changed benefits to natural enemies and antagonists from prey/host consumption

can differentially affect trophic levels [14, 34, 35]. (6) An asymmetrical enhancement of trophic levels within the food web may also result from the extent of species' reliance on shared resources [36]. The interaction strength between plants and their consumers is determined by consumers' feeding behaviour. For example, monophagous herbivores depend much more on a particular plant species than do omnivorous natural enemies. (7) Species-specific numerical and functional responses to the shared plant resource can favour members of one trophic level over the others [37, 38]. (8) Shared plant resources can modify a trophic cascade by altering species interactions with organisms outside the trophic cascade. For example, herbivores can suffer from increased interspecific competition [39, 40], and natural enemies can benefit from the presence of alternative prey [41] and can be exposed to altered intra- and interguild predation in the proximity of shared plant resources [42].

(9) Behavioural changes in species at different trophic levels can be induced by changes in relative availability of shared plant resources. For example, altered predation risk can induce behavioural changes in prey or hosts, such as predator avoidance behaviour and prey defensive responses [43]. These potentially costly behavioural changes may not only reduce prey/host reproduction but also feed back to higher-trophic-level consumers [44]. (10) Changes in relative availability of plant resources can directly affect the physiological condition of prey or hosts. This can occur as a consequence of altered intake of plant nutrients and toxins [45-47]. Altered prey or host quality can consequently affect higher-trophic-level consumers.

In summary, changes in the relative availability of plant resources can indirectly amplify or mitigate top-down control $[24,45,48]$. This analysis of potential interactions within and between second, third, and fourth trophic levels mediated by a shared plant resource (Table 1 ) is certainly not complete. Even though most of these interactions are known to some extent, this is to our knowledge the first synthesis of the ways in which differences in the abundance, availability, or quality of shared plant resources can lead to asymmetrical enhancements of fitness within and between trophic levels. More research is needed to quantify the importance of each of these interactions for asymmetrical fitness enhancements within food webs. In the past, several studies modelled the influence of omnivory on multitrophic interactions and its persistence in predator-prey systems (e.g., [49-51]). In particular, Van Rijn et al. [14] developed a stage-structured predator-prey-resource model to explore the conditions under which individual plants gain protection from the plant-provided resources, such as extrafloral nectar and pollen, that are accessible to predators and herbivores. Their analysis revealed that the herbivore equilibria settle to lower values in the presence of supplementary food and that for the third trophic level the spatial distribution of shared resources is crucial. In conclusion, this synthesis of potential interactions within and between trophic levels (Table 1) provides a basis for understanding how trophic cascades can be triggered by shared food resources so that the implications of changes in the abundance of these resources can be predicted. This can in turn lead to more appropriate outcome-driven deployment of biodiversity in applied community ecology such as conservation and pest management. These aspects are discussed in more detail below.

\section{Implications for Community Ecology}

Omnivory is central to food web dynamics because it diffuses the effects of consumption across the trophic spectrum [52]. It increases web connectance and shortens food chains [53], as well as stabilising community interactions [54]. A strong change in the relative availability of a shared plantderived resource, for example, as a result of plant invasion or extinction, may therefore alter the interactions among species (Figure 1) and as a result modify the entire food web [19]. A good example demonstrating the importance of plants in regulating the species composition of a community is the flower visitation web of a restored site in Mauritius [55]. Compared with a neighbouring, unrestored site that was heavily invaded by exotic plants, the restored site had a visitation web that was almost twice as species-rich and included visitors from several trophic levels. Also, the more complex pollinator community at the restored site allowed the native plant community to produce larger and heavier fruits with more seeds [55]. These results are supported by the broad literature on invasive and extinct plant species (e.g., [56-60]). Although invasive and endangered plant species are quite different in many aspects, both have the potential to play a disproportionately large role in shaping the community structure, especially if herbivores as well as omnivorous natural enemies and antagonists rely on these resources. 


\section{Implications for Biological Control}

About $36 \%$ of the world's food and fibre production is lost to plant pathogens, weeds, and insect pests (14\%, $12 \%$, and $10 \%$, resp.) despite all types of pest control measures [61]. While chemical pesticide use can increase yields of crops, these compounds can be broad-spectrum toxins, which have external costs such as effects on human health, lethal accidents, damage to the environment, and disruption of ecosystem function [62]. Top-down control of pests by natural enemies is therefore an extremely important alternative or complement to chemical pest control [8]. The ecosystem service of biological control that is provided by natural enemies has been valued at $>$ US $\$ 400$ billion per year globally [63]. Thus, the manipulation of top-down control within agriculture is of large economic as well as biological interest. However, modern agricultural practices suppress biological control and functional biodiversity, so "ecological engineering" techniques are needed to enhance natural enemies' contribution to sustainable agriculture [64]. However, an overall enhancement of natural enemy biodiversity does not necessarily result in greater top-down control of pest populations [65]. As this diversity increases, so does the potential for interference between natural enemy species [66], intraguild predation [67], changes in the antipredator behaviour of prey and hosts $[68,69]$, and redundancy among natural enemy species [70]. In fact, recent evidence indicates that increased insect pest suppression may be best achieved by suites of natural enemies that forage in complementary spatial and temporal ways $[70,71]$. The targeted deployment of specific plant resources that favour the fitness of selected biocontrol agents relative to their prey or host and their own antagonists can therefore boost top-down control [14, 72]. An asymmetrical enhancement of the fitness of targeted omnivorous predators and parasitoids can be achieved by using awareness of the factors and conditions given in Table 1. Implementing an asymmetrical enhancement of the effect of omnivorous biocontrol agents by the provision of alternative plant-derived food sources involves sophisticated mixtures of complementary crops in polycultures and intercropping, sophisticated weed management that preserves selective food sources, and the targeted cultivation of favourable noncrop species $[7,8,64,73,74]$. For example, targeted flowering plant species such as sweet alyssum, buckwheat, and sunflowers were intercropped with great success in Californian vineyards and vegetable fields. These plants increased the abundance of natural enemies such as hoverflies and parasitoids and consequently improved the biological control of aphids, leafhoppers, and thrips $[75,76]$. These measures for providing alternative plant resources are economically attractive and help to conserve biodiversity and its associated ecosystem services, such as pollination, nutrient cycling, erosion management, and recreation. $[8,77,78]$. Overall, the selective enhancement of top-down control is one of the most promising tools in pest management in largely monocultural agroecosystems to ensure the conservation of vital ecosystem services for improved food and fibre production, without compromising environmental integrity and public health [79].

\section{Conclusions}

This novel perspective emphasises that relative differences in the abundance of plant resources not only affect invertebrate herbivores but also directly affect the fitness and abundance of omnivorous natural enemies that rely on such food sources. Plant resources that are differentially used over several trophic levels have the potential to modify community structure and energy flow within ecosystems in more complex ways than is currently recognised. It is important that ecologists and environmental managers are aware of this complexity when attempting to manage and manipulate food webs to protect ecological communities against invaders, maintain biodiversity, or enhance top-down control of agricultural pests. A better understanding on how trophic cascades are triggered by shared food resources will certainly enhance the success of nature conservation programs and pest management schemes.

\section{Acknowledgments}

The authors thank Blas Lavandero, Don Vattala, Mauricio Urrútia, Salah Araj, Sam Scarratt, and Mark Wade for their useful suggestions, Matt Thomas, Teja Tscharntke, Bob Denno, Andrew Wilby, Bill Snyder, and Raphael Didham for discussing this research perspective, as well as Oliver Balmer, Jason Tylianakis, and Sue Zydenbos for their helpful comments on the manuscript. They gratefully acknowledge support from the Bio-Protection Research Centre, New Zealand. This study was funded by the Foundation for Research, Science and Technology, New Zealand (LINX 0303).

\section{References}

[1] S. B. Munch, M. L. Snover, G. M. Watters, and M. Mangel, "A unified treatment of top-down and bottom-up control of reproduction in populations," Ecology Letters, vol. 8, no. 7, pp. 691-695, 2005.

[2] G. A. Polis, "Why are parts of the world green? Multiple factors control productivity and the distribution of biomass," Oikos, vol. 86, no. 1, pp. 3-15, 1999.

[3] O. J. Schmitz, P. A. Hambäck, and A. P. Beckerman, "Trophic cascades in terrestrial systems: a review of the effects of carnivore removals on plants," American Naturalist, vol. 155, no. 2, pp. 141-153, 2000.

[4] J. H. Lawton and S. McNeill, "Between the devil and the deep blue sea: on the problem of being a herbivore," in Population Dynamics, R. M. Anderson, B. D. Turner, and L. R. Taylor, Eds., Blackwell Scientific Publications, Oxford, UK, 1979.

[5] F. L. Wäckers, P. C. J. van Rijn, and J. Bruin, Plant-Provided Food for Carnivorous Insects: A Protective Mutualism and Its Applications, Cambridge University Press, Cambridge, UK, 2005.

[6] F. L. Wäckers, J. Romeis, and P. van Rijn, "Nectar and pollen feeding by insect herbivores and implications for multitrophic interactions," Annual Review of Entomology, vol. 52, pp. 301323, 2007.

[7] D. A. Landis, S. D. Wratten, and G. M. Gurr, "Habitat management to conserve natural enemies of arthropod pests in agriculture," Annual Review of Entomology, vol. 45, pp. 175201, 2000. 
[8] G. Zehnder, G. M. Gurr, S. Kühne, M. R. Wade, S. D. Wratten, and E. Wyss, "Arthropod pest management in organic crops," Annual Review of Entomology, vol. 52, pp. 57-80, 2007.

[9] M. Coll and M. Guershon, "Omnivory in terrestrial arthropods: mixing plant and prey diets," Annual Review of Entomology, vol. 47, pp. 267-297, 2002.

[10] W. E. Snyder and E. W. Evans, "Ecological effects of invasive arthropod generalist predators," Annual Review of Ecology, Evolution, and Systematics, vol. 37, pp. 95-122, 2006.

[11] G. A. Polis and D. R. Strong, "Food web complexity and community dynamics," American Naturalist, vol. 147, no. 5, pp. 813-846, 1996.

[12] M. D. Eubanks and J. D. Styrsky, "Effects of plant feeding on the performance of omnivorous "predators"'” in PlantProvided Food and Herbivore-Carnivore Interactions: A Protective Mutualism and Its Applications, F. L. Wäckers, P. C. J. van Rijn, and J. Bruin, Eds., Cambridge University Press, Cambridge, UK, 2005.

[13] K. A. Robinson, M. Jonsson, S. D. Wratten, M. R. Wade, and H. L. Buckley, "Implications of floral resources for predation by an omnivorous lacewing," Basic and Applied Ecology, vol. 9, no. 2, pp. 172-181, 2008.

[14] P. C. J. van Rijn, Y. M. van Houten, and M. W. Sabelis, "How plants benefit from providing food to predators even when it is also edible to herbivores," Ecology, vol. 83, no. 10, pp. 26642679, 2002.

[15] M. D. Eubanks and R. F. Denno, "The ecological consequences of variation in plants and prey for an omnivorous insect," Ecology, vol. 80, no. 4, pp. 1253-1266, 1999.

[16] L. R. Baggen, G. M. Gurr, and A. Meats, "Flowers in tritrophic systems: mechanisms allowing selective exploitation by insect natural enemies for conservation biological control," Entomologia Experimentalis et Applicata, vol. 91, no. 1, pp. $155-161,1999$.

[17] J. C. Lee and G. E. Heimpel, "Impact of flowering buckwheat on Lepidopteran cabbage pests and their parasitoids at two spatial scales," Biological Control, vol. 34, no. 3, pp. 290-301, 2005.

[18] J. A. Rosenheim, T. E. Glik, R. E. Goeriz, and B. Rämert, "Linking a predator's foraging behavior with its effects on herbivore population suppression," Ecology, vol. 85, no. 12, pp. 3362-3372, 2004.

[19] M. L. Pace, J. J. Cole, S. R. Carpenter, and J. F. Kitchell, "Trophic cascades revealed in diverse ecosystems," Trends in Ecology \& Evolution, vol. 14, no. 12, pp. 483-488, 1999.

[20] K. Winkler, F. L. Wäckers, A. Stingli, and J. C. van Lenteren, "Plutella xylostella (diamondback moth) and its parasitoid Diadegma semiclausum show different gustatory and longevity responses to a range of nectar and honeydew sugars," Entomologia Experimentalis et Applicata, vol. 115, no. 1, pp. 187192, 2005.

[21] B. Lavandero, S. D. Wratten, R. K. Didham, and G. Gurr, "Increasing floral diversity for selective enhancement of biological control agents: a double-edged sward?" Basic and Applied Ecology, vol. 7, no. 3, pp. 236-243, 2006.

[22] S. E. Araj, S. Wratten, A. Lister, and H. Buckley, "Floral diversity, parasitoids and hyperparasitoids-a laboratory approach," Basic and Applied Ecology, vol. 9, no. 5, pp. 588-597, 2008.

[23] P. Kehrli and S. Bacher, "Differential effects of flower feeding in an insect host-parasitoid system," Basic and Applied Ecology, vol. 9, no. 6, pp. 709-717, 2008.

[24] M. Jonsson, S. D. Wratten, K. A. Robinson, and S. A. Sam, "The impact of floral resources and omnivory on a four trophic level food web," Bulletin of Entomological Research, vol. 99, no. 3, pp. 275-285, 2009.

[25] L. A. Berndt and S. D. Wratten, "Effects of alyssum flowers on the longevity, fecundity, and sex ratio of the leafroller parasitoid Dolichogenidea tasmanica," Biological Control, vol. 32, no. 1, pp. 65-69, 2005.

[26] D. L. J. Quicke, Parasitic Wasps, Chapman \& Hall, London, UK, 1997.

[27] H. F. Howe and L. C. Westley, "Ecology of pollination and seed dispersal," in Plant Ecology, M. J. Crawley, Ed., Blackwell Science, Oxford, UK, 1997.

[28] J. P. Rosenthal and M. R. Berenbaum, Herbivores: Their Interactions with Secondary Plant Metabolites, Academic Press, San Diego, Calif, USA, 1991.

[29] P. J. Ode, "Plant chemistry and natural enemy fitness: effects on herbivore and natural enemy interactions," Annual Review of Entomology, vol. 51, pp. 163-185, 2006.

[30] H. G. Baker and I. Baker, "Floral nectar sugar constituents in relation to pollinator type," in Handbook of Experimental Pollination Biology, C. E. Jones and R. J. Little, Eds., Scientific and Academic Editions, New York, NY, USA, 1983.

[31] H. D. Vattala, S. D. Wratten, C. B. Phillips, and F. L. Wäckers, "The influence of flower morphology and nectar quality on the longevity of a parasitoid biological control agent," Biological Control, vol. 39, no. 2, pp. 179-185, 2006.

[32] F. L. Wäckers, "Gustatory response by the hymenopteran parasitoid Cotesia glomerata to a range of nectar and honeydew sugars," Journal of Chemical Ecology, vol. 25, no. 12, pp. 28632877, 1999.

[33] C. A. Edwards, K. D. Sunderland, and K. S. George, "Studies on polyphagous predators of cereal aphids," Journal of Applied Ecology, vol. 16, pp. 811-823, 1979.

[34] J. M. Bullock, R. E. Kenward, and R. S. Hails, Dispersal Ecology, Blackwell Publishing, Oxford, UK, 2002.

[35] S. D. Wratten, M. H. Bowie, J. M. Hickman, A. M. Evans, J. R. Sedcole, and J. M. Tylianakis, "Field boundaries as barriers to movement of hover flies (Diptera: Syrphidae) in cultivated land," Oecologia, vol. 134, no. 4, pp. 605-611, 2003.

[36] R. T. Paine, "Food-web analysis through field measurement of per capita interaction strength," Nature, vol. 355, no. 6355, pp. 73-75, 1992.

[37] O. Gilg, B. Sittler, B. Sabard et al., "Functional and numerical responses of four lemming predators in high arctic Greenland," Oikos, vol. 113, no. 2, pp. 193-216, 2006.

[38] S. M. Redpath and S. J. Thirgood, "Numerical and functional responses in generalist predators: hen harriers and peregrines on Scottish grouse moors," Journal of Animal Ecology, vol. 68, no. 5, pp. 879-892, 1999.

[39] R. F. Denno, M. S. McClure, and J. R. Ott, "Interspecific interactions in phytophagous insects: competition reexamined and resurrected," Annual Review of Entomology, vol. 40, pp. 297-331, 1995.

[40] A. J. A. Stewart, "Interspecific competition reinstated as an important force structuring insect herbivore communities," Trends in Ecology \& Evolution, vol. 11, pp. 233-234, 1996.

[41] R. J. Morris, O. T. Lewis, and H. C. J. Godfray, "Experimental evidence for apparent competition in a tropical forest food web," Nature, vol. 428, no. 6980, pp. 310-313, 2004.

[42] D. L. Finke and R. F. Denno, "Spatial refuge from intraguild predation: implications for prey suppression and trophic cascades," Oecologia, vol. 149, no. 2, pp. 265-275, 2006.

[43] E. H. Nelson, C. E. Matthews, and J. A. Rosenheim, "Predators reduce prey population growth by inducing changes in prey behavior," Ecology, vol. 85, no. 7, pp. 1853-1858, 2004. 
[44] E. H. Nelson, "Predator avoidance behavior in the pea aphid: costs, frequency, and population consequences," Oecologia, vol. 151, no. 1, pp. 22-32, 2007.

[45] M. A. Urrutia C, M. R. Wade, C. B. Phillips, and S. D. Wratten, "Influence of host diet on parasitoid fitness: unravelling the complexity of a temperate pastoral agroecosystem," Entomologia Experimentalis et Applicata, vol. 123, no. 1, pp. 63-71, 2007.

[46] H. C. J. Godfray, Parasitoids: Behavioural and Evolutionary Ecology, Princeton University Press, Princeton, NJ, USA, 1993.

[47] R. Senrayan and R. S. Annadurai, "Influence of host's food plant and habitat on Anastrus ramakrshnae (Mani) (Hym., Eupelmidae), an egg parasitoid of Coridius obscurus (Fab.) (Het., Pentatomidae)," Journal of Applied Entomology, vol. 112, pp. 237-243, 1991.

[48] J. A. Harvey, N. M. van Dam, and R. Gols, "Interactions over four trophic levels: foodplant quality affects development of a hyperparasitoid as mediated through a herbivore and its primary parasitoid," Journal of Animal Ecology, vol. 72, no. 3, pp. 520-531, 2003.

[49] M. van Baalen, V. Křivan, P. C. J. van Rijn, and M. W. Sabelis, "Alternative food, switching predators, and the persistence of predator-prey systems," American Naturalist, vol. 157, no. 5, pp. 512-524, 2001.

[50] V. Krrivan and S. Diehl, "Adaptive omnivory and species coexistence in tri-trophic food webs," Theoretical Population Biology, vol. 67, no. 2, pp. 85-99, 2005.

[51] J. Kean, S. Wratten, J. Tylianakis, and N. Barlow, "The population consequences of natural enemy enhancement, and implications for conservation biological control," Ecology Letters, vol. 6, no. 7, pp. 604-612, 2003.

[52] D. Simberloff and P. Stiling, "How risky is biological control?" Ecology, vol. 77, no. 7, pp. 1965-1974, 1996.

[53] W. G. Sprules and J. E. Bowerman, "Omnivory and food chain length in zooplankton food webs," Ecology, vol. 69, no. 2, pp. 418-426, 1988.

[54] W. F. Fagan, "Omnivory as a stabilizing feature of natural communities," American Naturalist, vol. 150, no. 5, pp. 554567, 1997.

[55] C. N. Kaiser, Functional integrity of plant-pollinator communities in restored habitats in Mauritius, Dissertation, Universität Zürich, 2006.

[56] J. Belnap, S. L. Phillips, S. K. Sherrod, and A. Moldenke, "Soil biota can change after exotic plant invasion: does this affect ecosystem processes?" Ecology, vol. 86, no. 11, pp. 3007-3017, 2005.

[57] B. J. Brown, R. J. Mitchell, and S. A. Graham, "Competition for pollination between an invasive species (purple loosestrife) and a native congener," Ecology, vol. 83, no. 8, pp. 2328-2336, 2002.

[58] J. E. Duffy, "Biodiversity and ecosystem function: the consumer connection," Oikos, vol. 99, no. 2, pp. 201-219, 2002.

[59] W. H. van der Putten, P. C. De Ruiter, T. M. Bezemer, J. A. Harvey, M. Wassen, and V. Wolters, "Trophic interactions in a changing world," Basic and Applied Ecology, vol. 5, no. 6, pp. 487-494, 2004.

[60] I. Bartomeus, M. Vilà, and L. Santamaría, "Contrasting effects of invasive plants in plant-pollinator networks," Oecologia, vol. 155, no. 4, pp. 761-770, 2008.

[61] G. N. Agrios, Plant Pathology, Elsevier Academic Press, Amsterdam, The Netherlands, 5th edition, 2005.

[62] G. J. Devine and M. J. Furlong, "Insecticide use: contexts and ecological consequences," Agriculture and Human Values, vol. 24, no. 3, pp. 281-306, 2007.
[63] R. Costanza, R. d'Arge, R. de Groot et al., "The value of the world's ecosystem services and natural capital," Nature, vol. 387, no. 6630, pp. 253-260, 1997.

[64] G. M. Gurr, S. D. Wratten, and M. A. Altieri, Ecological Engineering for Pest Managment Advances in Habitat Manipulation for Arthropods, CSIRO Publishing, Collingwood, Australia, 2004.

[65] B. J. Cardinale, D. S. Srivastava, J. E. Duffy et al., "Effects of biodiversity on the functioning of trophic groups and ecosystems," Nature, vol. 443, no. 7114, pp. 989-992, 2006.

[66] M. D. Moran and L. E. Hurd, "Short-term responses to elevated predator densities: noncompetitive intraguild interactions and behavior," Oecologia, vol. 98, no. 3-4, pp. 269-273, 1994.

[67] D. L. Finke and R. F. Denno, "Predator diversity dampens trophic cascades," Nature, vol. 429, no. 6990, pp. 407-410, 2004.

[68] O. J. Schmitz, V. Krivan, and O. Ovadia, "Trophic cascades: the primacy of trait-mediated indirect interactions," Ecology Letters, vol. 7, no. 2, pp. 153-163, 2004.

[69] R. P. Prasad and W. E. Snyder, "Diverse trait-mediated interactions in a multi-predator, multi-prey community," Ecology, vol. 87, no. 5, pp. 1131-1137, 2006.

[70] P. Casula, A. Wilby, and M. B. Thomas, "Understanding biodiversity effects on prey in multi-enemy systems," Ecology Letters, vol. 9, no. 9, pp. 995-1004, 2006.

[71] A. R. Ives, B. J. Cardinale, and W. E. Snyder, "A synthesis of subdisciplines: predator-prey interactions, and biodiversity and ecosystem functioning," Ecology Letters, vol. 8, no. 1, pp. 102-116, 2005.

[72] J. M. Tylianakis, R. K. Didham, and S. D. Wratten, "Improved fitness of aphid parasitoids receiving resource subsidies," Ecology, vol. 85, no. 3, pp. 658-666, 2004.

[73] D. A. Andow, "Vegetational diversity and arthropod population response," Annual Review of Entomology, vol. 36, no. 1, pp. 561-586, 1991.

[74] T. Tscharntke, A. M. Klein, A. Kruess, I. Steffan-Dewenter, and C. Thies, "Landscape perspectives on agricultural intensification and biodiversity-ecosystem service management," Ecology Letters, vol. 8, no. 8, pp. 857-874, 2005.

[75] R. Colfer, "Using habitat management to improve biological control on commercial organic farms California," in California Conference on Biological Control IV, M. S. Hoddle, Ed., pp. 55-62, Center for Biological Control, College of Natural Resources, University of California, Berkley, Calif, USA, July 2004.

[76] C. I. Nicholls, M. P. Parrella, and M. A. Altieri, "Reducing the abundance of leafhoppers and thrips in a northern California organic vineyard through maintenance of full season floral diversity with summer cover crops," Agricultural and Forest Entomology, vol. 2, no. 2, pp. 107-113, 2000.

[77] M. Loreau, S. Naeem, P. Inchausti et al., "Ecology: biodiversity and ecosystem functioning: current knowledge and future challenges," Science, vol. 294, no. 5543, pp. 804-808, 2001.

[78] G. C. Daily and P. A. Matson, "Ecosystem services: from theory to implementation," Proceedings of the National Academy of Sciences of the United States of America, vol. 105, no. 28, pp. 9455-9456, 2008.

[79] D. Tilman, K. G. Cassman, P. A. Matson, R. Naylor, and S. Polasky, "Agricultural sustainability and intensive production practices," Nature, vol. 418, no. 6898, pp. 671-677, 2002. 

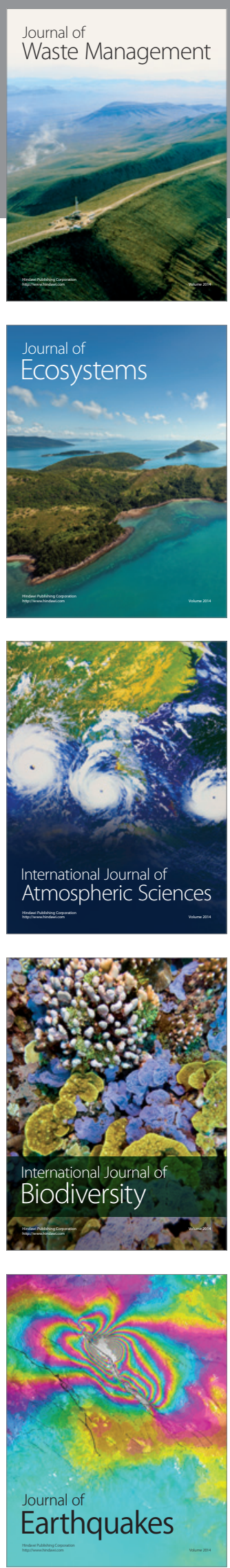
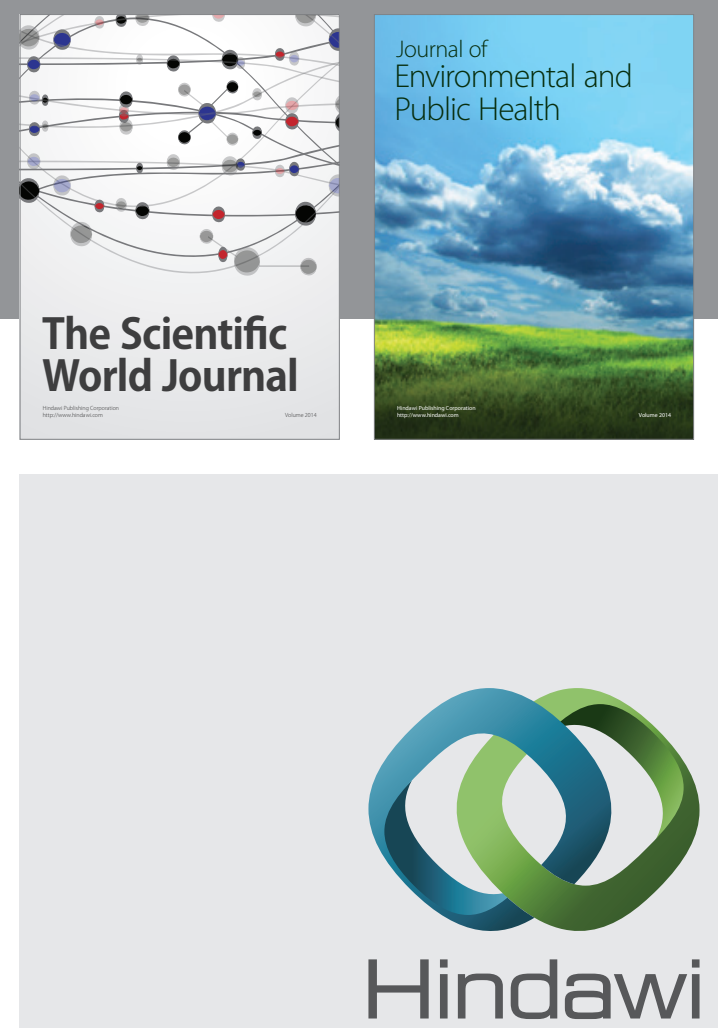

Submit your manuscripts at

http://www.hindawi.com
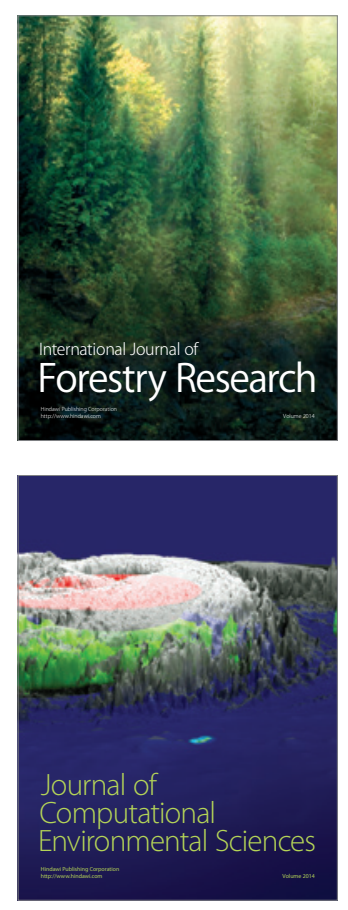
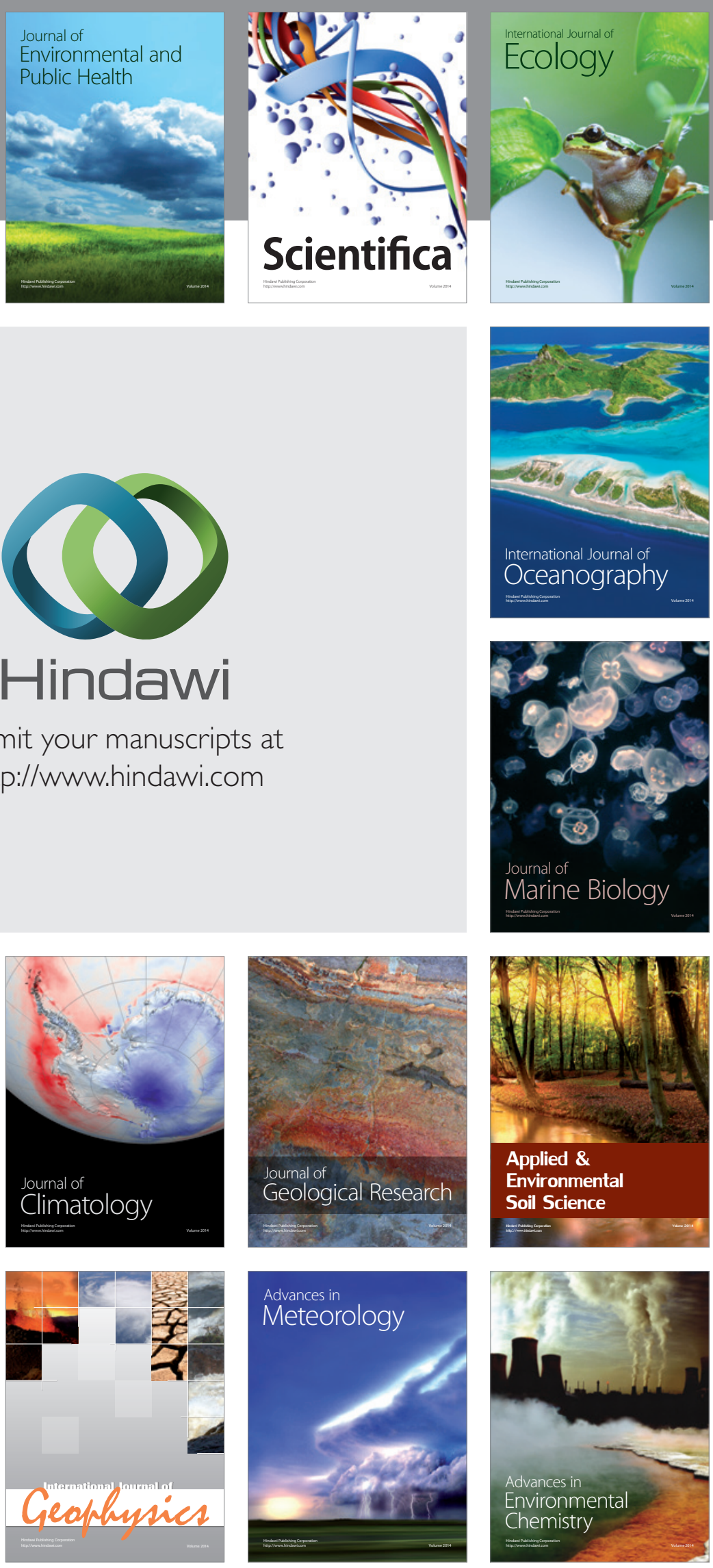